\title{
Randomized clinical trial of an elastomeric sealant for hemostasis in thoracic aortic surgery
}

\author{
Shigeki Morita ${ }^{1}$ (1) $\cdot$ Takehisa Matsuda $^{2} \cdot$ Tadashi Tashiro $^{3} \cdot$ Tatsuhiko Komiya $^{4} \cdot$ Hitoshi Ogino $^{5}$. \\ Nobuhiko Mukohara ${ }^{6} \cdot$ Ryuji Tominaga $^{7}$
}

Received: 4 April 2019 / Accepted: 30 June 2019 / Published online: 12 July 2019

(c) The Author(s) 2019

\begin{abstract}
Objectives This study aimed to demonstrate the efficacy and safety of a newly developed elastomeric sealant, which does not require any blood coagulation system to exert its effect, during thoracic aortic surgery.

Methods This is a multicenter, randomized study conducted in six hospitals in Japan. A total of 81 patients undergoing replacement surgery of a thoracic aortic aneurysm using cardiopulmonary bypass were randomized with a ratio of 2-:1 for those patients designated to receive the sealant (Group S, 54 patients) or those without the usage of the sealant (Group C, 27 patients). The primary endpoints were bleeding from each anastomosis at two time points: (1) immediately before applying protamine and (2) 15 min after applying protamine. The patients were followed for 6 months.

Results The number of anastomoses checked for bleeding was 196 in Group S and 117 in Group C. Before protamine sulfate administration, complete hemostasis was obtained in 155 anastomoses (79\%) in Group S compared to 45 anastomoses (38\%) in Group C $(p<0.001)$. Fifteen minutes after the administration of protamine sulfate infusion, bleeding stopped completely in 173 anastomoses $(88 \%)$ in Group S and in 71 anastomoses $(61 \%, p<0.001)$ in Group C. Between the two groups, there were no marked differences in the patient background or in the incidence of major adverse events.

Conclusions The sealant is effective in achieving hemostasis, even under fully heparinized conditions. The novel sealant is safe and effective in thoracic aortic surgery, one of the most demanding surgical situations for hemostasis.
\end{abstract}

Keywords Surgical sealant $\cdot$ Thoracic aneurysm $\cdot$ Hemostasis

Shigeki Morita

morita.shigeki.mu@mail.hosp.go.jp

1 Department of Thoracic and Cardiovascular Surgery, Clinical Research Institute, National Hospital Organization Kyushu Medical Center, 1-8-1 Jigyohama, Fukuoka 810-8563, Japan

2 Division of Biomedical Engineering, Graduate School of Medical Science, Kyushu University, Fukuoka, Japan

3 Department of Cardiovascular Surgery, University of Fukuoka Medical School, Fukuoka, Japan

4 Department of Cardiovascular Surgery, Kurashiki Central Hospital, Kurashiki, Okayama, Japan

5 Department of Cardiovascular Surgery, National Cardiovascular and Research Center, Suita, Osaka, Japan

6 Department of Cardiovascular Surgery, Hyogo Brain and Heart Center, Himeji, Japan

7 Division of Cardiovascular Surgery, Graduate School of Medical Science, Kyushu University, Fukuoka, Japan

\section{Introduction}

Effective hemostasis is the key to the success of aortic surgery. Particularly in patients undergoing thoracic aorta replacement using cardiopulmonary bypass, the mandatory usage of heparin and occasional complication of coagulopathy make it difficult to achieve hemostasis. Although several surgical sealants have been introduced clinically [1-4], each has a number of limitations such as the inherent risk of infection due to the biological nature of the sealant, the requirement of an intact hematological coagulation system for the sealants to function, a weakened hemostatic function with the presence of liquid, and a lack of an elastomeric property causing compliance mismatch with the native aorta.

One of the authors (T.M.) developed an elastomeric sealant with a highly reactive copolymer of polyethylene glycol (PEG) and polypropylene glycol (PPG), in which both ends were capped with non-carcinogenic fluorinated hexamethylene diisocyanate [5, 6] (Fig. 1). The sealant is provided as a 
Fig. 1 The chemical structure of the sealant. The liquid PEG-PPG copolymer segment (Polyols) has a very high water uptake characteristic, and the fluorinated isocyanate group (Isocyanate) reacts with water to form cross-linking and polymerization

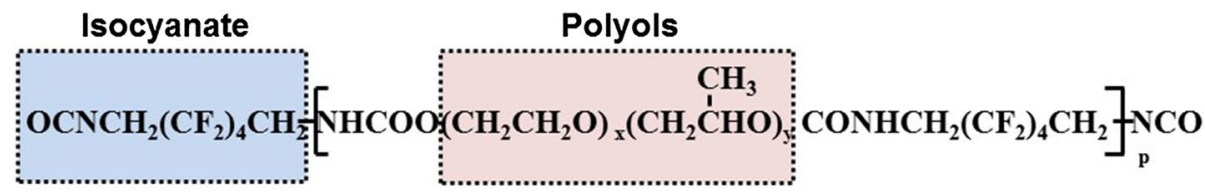

Highly reactive, non-carcinogenic Diisocyanate residue

\author{
Hydrophilic, viscous polyols
}

viscous liquid in a syringe. Once applied to the anastomosis, the polymerization reaction proceeds via successive reaction of the isocyanate group with water molecules diffused into the sealant. Therefore, this sealant does not need any additional agents to initiate the reaction. After polymerization, the sealant exhibits an elastomeric property, following the pulsatile movement of the aorta. Testing in several animal models showed the sealant to have excellent hemostatic properties and a beneficial compliant nature [7, 8]. Satisfactory hemostasis was obtained in experimental models of end-to-end anastomosis of canine and porcine carotid arteries using only four stitches of simple interrupted sutures under fully heparinized conditions. Encouraged by these results, we hypothesized that the application of the sealant would improve hemostasis in thoracic aorta replacement with vascular prosthesis, even under heparinized conditions. After receiving approval of the protocol from the Pharmaceuticals and Medical Device Agency of Japan (PMDA), this randomized, multicenter trial was performed in patients undergoing surgery of the thoracic aorta.

\section{Patients and methods}

\section{Patients}

This is a multicenter, randomized, controlled, open-label study conducted in six hospitals in Japan. The inclusion criteria were (1) patients scheduled for thoracic aneurysm repair with replacement of the aorta, (2) between 20 and 79 years of age, and (3) able to give their written informed consent.

The exclusion criteria were emergent surgery, a ruptured aneurysm, reoperation through the same incision, severe infection, anemia (hemoglobin level $<9.0 \mathrm{~g} / 100 \mathrm{ml}$ ), liver dysfunction (total bilirubin level $>3.0 \mathrm{mg} / 100 \mathrm{ml}$ ), renal dysfunction (creatinine level $>2.0 \mathrm{mg} / 100 \mathrm{ml}$ ), coagulopathy (fibrin degradation product $>30 \mu \mathrm{g} / \mathrm{ml}$, or platelet count $<100,000 / \mathrm{mm}^{2}$ ), diabetes (HbA1c $>8.0 \%$ ), and receiving steroids. Patients who were scheduled for aortic root surgeries, such as Bentall operation or valve-sparing root replacement, were also excluded. We excluded emergency cases because we thought that obtaining informed consent and waiting for the allocation process for randomization were impractical in patients with acute aortic dissection or impending rupture of the aortic aneurysm. In addition, increasing the number of confounding factors related to acute cases was deemed likely to cause further inhomogeneity of the patient population, which might have hampered the comparison. Aortic root replacement was excluded because it was difficult to inspect the anastomosis and judge the hemostatic status after the heart was reperfused.

The study was approved by the internal review board of each hospital and also by the PMDA. Written informed consent was obtained from each patient. The study was registered to the University Hospital Medical Information Network (UMIN)-Clinical Trial Registry (CTR) system with an ID of UMIN000023683. The UMIN-CTR system is accepted by the International Committee of Medical Journal Editors (ICMJE). We waited to submit our findings to the journal until the sealant had been approved and become commercially available; following such approval, large-scale post-market surveillance is routinely required by PMDA to further clarify the safety issues, especially regarding infection and inflammation of the product (please refer to "Discussion" regarding the issue). For this reason, it took a long time to submit the paper once this clinical study had been completed.

\section{Surgical sealant}

The sealant is a viscous liquid of diisocyanate-endcapped prepolymer (Matsudaito, Sanyo Kasei Co., Ltd., Kyoto, Japan). The liquid PEG-PPG copolymer segment has a very high water uptake characteristic, whereas the fluorinated isocyanate group reacts with water to form cross-linking and polymerization (Fig. 1). Although some diisocyanates, such as tolylene diisocyanate, are known carcinogenic substances, the fluorinated hexamethylene diisocyanate used in this sealant has no known carcinogenic or mutagenic potential [6].

A major favorable feature of this sealant is its hydrophilic property, which allows the sealant to penetrate places where water molecules exist and start reacting with water to form a seal tightly attached to the tissue (Fig. 2). According to the manufacturer's data, the curing time (the time required to complete polymerization) at 20,28 , and $37^{\circ} \mathrm{C}$ was 230 , 
Fig. 2 A schematic presentation of the process of the sealant reaction when applied to tissue. Because the tissue surface is always moistened and covered with water, the sealant starts reacting immediately when applied to the tissue surface. The sealant penetrates places where water molecules exist due to its hydrophilic nature and starts reacting with the water to form a seal tightly attached to the tissue. During the reaction, small carbon dioxide gas bubbles are generated by the sealant
Tissue covered with a thin layer of water

A
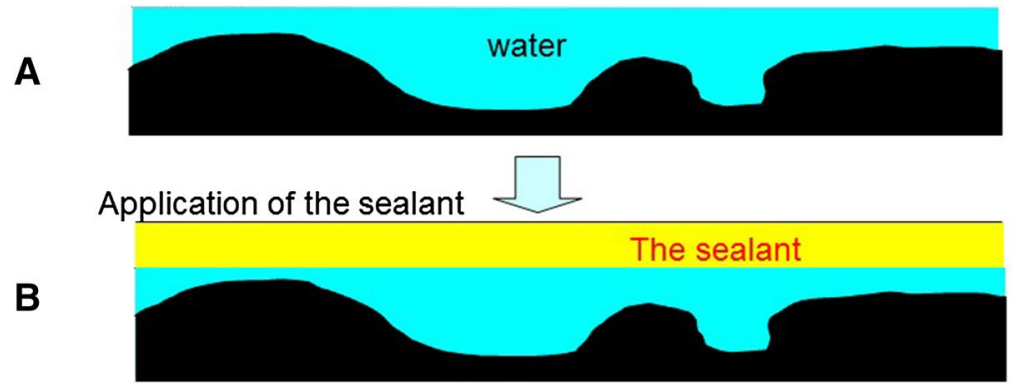

Water adsorption and reaction $\square$ The adsorption of the layer of water and reaction

C
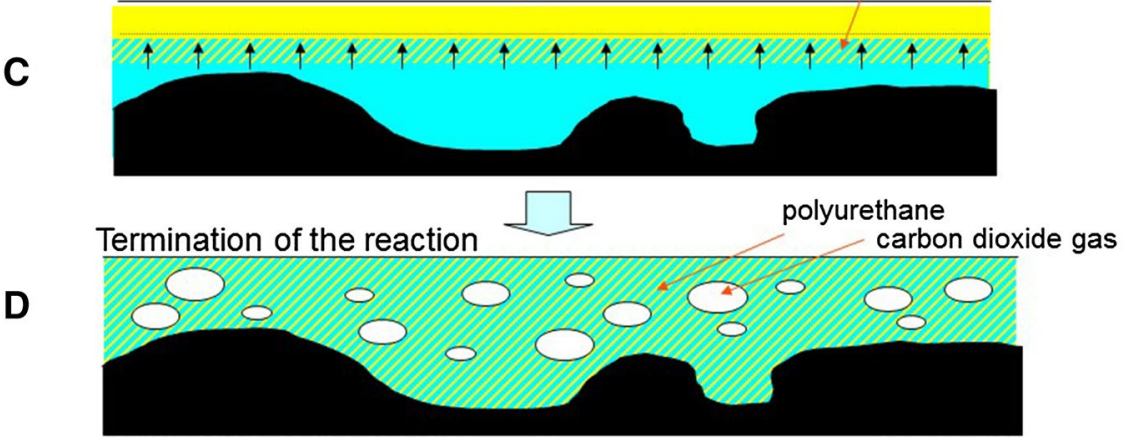

150, and $80 \mathrm{~s}$, respectively. For practical purposes, we asked surgeons to press the anastomosis over the silicon strip after applying the sealant for at least $3 \mathrm{~min}$. The design concept, detailed synthesis procedure, curing rate, elastomeric properties, tissue adhesive property, and workability have been described previously [5, 6].

Besides the animal studies described above, small-animal experiments, mainly involving the subcutaneous implantation of the sealant in rats, were performed following "ISO 10993-6:1994. Biological evaluation of medical devices Part 6: Test for local effects after implantation." The experiments showed no adverse effects and the results were reported to the PMDA before starting this clinical trial.

\section{Study protocol}

The patients were randomly allocated into two groups: Group S (patients with the sealant) and Group C (control group), at a ratio of 2:1, respectively, using a computer-generated randomization protocol. Our data from large-animal experiments showed that the number of patients required to show a difference in hemostasis was 30 per group. This was based on the assumption that successful hemostasis rates obtained before protamine administration were $65 \%$ and $30 \%$ in Groups $\mathrm{S}$ and $\mathrm{C}$, respectively, with an average of three anastomoses per patients. In Group $S$, the total number of patients was set at 60 , because the PMDA required us to include 60 patients to clear the safety issue by increasing the sensitivity for examining the adverse effects of the sealant.
In Group S, the sealant was applied to the anastomosis when each anastomosis was made. No other hemostatic material was allowed to be used before the primary endpoint evaluation. Patients in Group $\mathrm{C}$ were allowed to be treated throughout the procedure with any hemostatic method or material available, except for the current elastomeric sealant.

\section{Primary endpoints}

We set two primary endpoints. The first primary endpoint was bleeding from the anastomosis immediately before the administration of protamine sulfate. The presence of bleeding was judged by the inspection of at least two surgeons and recorded as "yes" or "no," in an "all or none" manner; for example, even if bleeding was noted from only one needle hole, it was still recorded as "yes." A judgement of "no" for bleeding therefore implies "complete hemostasis." The second primary endpoint was bleeding from the anastomosis 15 min after the start of protamine administration. Bleeding was judged in the same manner as in the first primary endpoint evaluation.

\section{Secondary endpoints}

The following items were used as secondary endpoints: (1) the length of time between the start of protamine administration and the end of surgery, (2) the amount of bleeding during surgery, (3) the amount of transfusion, and (4) additional hemostatic procedures after protamine sulfate administration. 


\section{Follow-up for adverse events}

Patients were followed up for 6 months after the surgery. Each patient underwent chest computed tomography (CT) before discharge. A physical examination and chest X-ray were performed at 6 months after the surgery. Any adverse events were requested to be reported with specified report sheets. The length of the follow-up (6 months) was established based on a request from the PMDA. Apart from the study, a longer follow-up for gathering data for adverse events was performed as post-marketing surveillance as requested by the PMDA with a larger number of patients followed for at least 1 year, which has been completed recently.

All data were collected and recorded on a standardized report sheet, and the accuracy was confirmed and audited at the Clinical Research Department/Institute of each hospital.

\section{Statistics}

With categorical variables, such as "bleeding (yes or no)" in the primary endpoints, Fisher's exact test was used for the statistical comparison. With continuous variables, such as the time from the start of protamine sulfate administration to the end of surgery, bleeding volume, or transfusion volume, a $t$ test was used for the statistical comparison. A two-sided significance level of 5\% and a two-sided confidence level of $95 \%$ were used to determine the significant differences between the two groups.

\section{Results}

\section{Patient allocation}

Between December 6, 2006 and September 25, 2009, a total of 86 patients gave their informed consent and were allocated to Groups $\mathrm{S}(n=59)$ and $\mathrm{C}(n=27)$ (Fig. 3). Four patients were excluded from Group $\mathrm{S}$ before surgery. Of these four patients, surgery was postponed in two and they did not enter the study thereafter. The other two patients were excluded because severe stenosis of the cerebral artery was found preoperatively in one, while the other developed dissection of the subclavian artery (SCA) during end-toside anastomosis of the vascular prosthesis to the SCA in preparation for cardiopulmonary bypass as the arterial blood return route. Thus, 55 patients ultimately underwent surgery in Group S. One patient allocated to Group S was excluded after the surgery; this patient underwent total arch replacement and the sealant was applied to each anastomosis, but a large part of the sealant was removed to check the bleeding point, which resulted in the removal of most of the adventitia. The sealant was not reapplied thereafter. The case was treated as a protocol deviation and was not included in the primary endpoint evaluation, but was still followed for 6 months. The study therefore ultimately consisted of 54 patients receiving sealant (Group S) and 27 not receiving the sealant (Group C).

Follow-up was completed in 51 patients in Group $\mathrm{S}$ and 23 patients in Group C. The reasons for incomplete
Fig. 3 Patient allocation. Fiftyfour patients in Group $\mathrm{S}$ and 27 patients in Group C underwent the primary endpoint evaluation

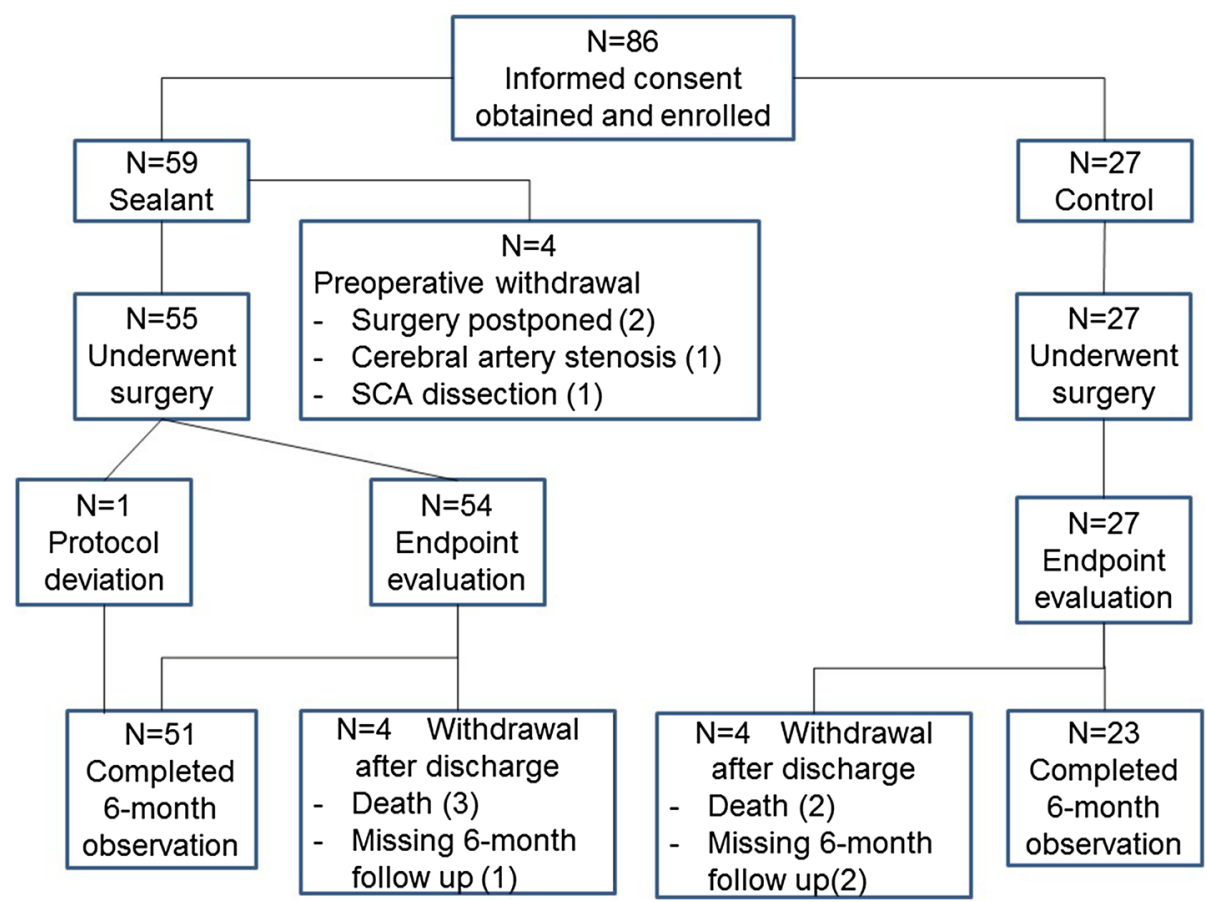


follow-up in the eight patients were deaths in five (three patients in Group S, two patients in Group C) and a lack of 6-month follow-up data in three (one patient in Group S, two patients in Group C). Patients' background data are shown in Table 1. There were no significant differences in patients' demographics or background characteristics between the two groups.

\section{Operative procedures and technique of applying the sealant}

Operative procedures and the anastomotic sites checked for bleeding are shown in Table 2 . Of the 81 patients, more than half (42 patients) underwent total aortic arch replacement. Percentage of total arch replacement in Group S was $48 \%$ and it was smaller than that of Group C (63\%), but it did not reach statistical significance $(p=0.209)$. The numbers of cardiac procedures other than aortic surgery performed at the time of surgery are summarized in the lower part of Table 1.
A total of 313 anastomoses were checked for bleeding. There were 196 anastomoses in Group S and 117 in Group C (Table 2). The types of anastomoses ("aorta-graft," "graft-graft," "arch vessel-graft," etc.) are summarized in Table 3. In Group S, the sealant was applied to the anastomoses when the anastomosis was made. A strip of silicon was used, when indicated, to apply the sealant to the anastomosis. As previously described, the judgment of "no bleeding" was made only when complete hemostasis was obtained.

\section{Endpoint results}

As shown in Fig. 4, complete hemostasis was obtained in $79 \%$ of the patients in Group S but only in $38 \%$ in Group C. Similarly, the rate of complete hemostasis $15 \mathrm{~min}$ after starting protamine administration was significantly higher in Group S $(88 \%)$ than in Group C $(61 \%)(p<0.001)$. Individual hemostasis rate according to the type of anastomoses is given in Table 3 .

Table 1 The preoperative background characteristics

\begin{tabular}{|c|c|c|c|}
\hline Items & $\begin{array}{l}\text { Group S }(N=54) \\
N(\%)\end{array}$ & $\begin{array}{l}\text { Group C }(N=27) \\
N(\%)\end{array}$ & $p$ value \\
\hline \multicolumn{4}{|l|}{ Gender } \\
\hline Male & $38(70.4 \%)$ & $19(70.4 \%)$ & 1.000 \\
\hline Female & $16(29.6 \%)$ & $8(29.6 \%)$ & \\
\hline Hypertension & $45(83.3 \%)$ & $24(88.9 \%)$ & 0.658 \\
\hline Hyperlipidemia & $16(29.6 \%)$ & $24(37.0 \%)$ & 0.742 \\
\hline Diabetes & $7(13.0 \%)$ & $10(18.5 \%)$ & 0.615 \\
\hline \multirow[t]{2}{*}{ Cerebrovascular disease } & $5(9.3 \%)$ & $5(7.4 \%)$ & 1.000 \\
\hline & Mean (S.D.) & Mean (S.D.) & $\mathrm{p}$-value \\
\hline Age (year) & $67.4(10.3)$ & $67.1(7.1)$ & 0.873 \\
\hline Body weight (kg) & $63.8(14.2)$ & $65.8(9.8)$ & 0.463 \\
\hline Systolic BP (mm Hg) & $126(15.9)$ & $131(19.6)$ & 0.234 \\
\hline Heart rate $\left(\min ^{-1}\right)$ & $68.3(12.6)$ & $65.9(9.5)$ & 0.382 \\
\hline Platelet count $\left(\times 10^{3} / \mu \mathrm{L}\right)$ & $207.8(54.1)$ & $181.0(44.4)$ & 0.046 \\
\hline $\mathrm{FDP}(\mu \mathrm{g} / \mathrm{mL})$ & $9.19(7.41), N=42$ & $6.78(6.44), N=21$ & 0.069 \\
\hline FDP-E (ng/mL) & $57.18(52.30), N=12$ & $58.55(51.53), N=6$ & 0.779 \\
\hline CPB time (min) & $216.3(62.5)$ & $216.1(74.4)$ & 0.715 \\
\hline Cardiac arrest time (min) & $103.3(54.1)$ & $104.7(54.7)$ & 0.908 \\
\hline \multicolumn{4}{|l|}{ Concomitant procedures } \\
\hline Aortic valve replacement & 10 & 4 & 0.678 \\
\hline CABG & 9 & 1 & 0.095 \\
\hline Pulmonary vein isolation & 0 & 1 & 0.155 \\
\hline Maze procedure & 1 & 0 & 0.477 \\
\hline Tricuspid annuloplasty & 0 & 1 & 0.155 \\
\hline Mitral annuloplasty & 0 & 1 & 0.155 \\
\hline
\end{tabular}

$B P$ blood pressure, $C A B G$ coronary artery bypass grafting, $C P B$ cardiopulmonary bypass, $F D P-E$ fibrin degradation product e fraction 
Table 2 The operative procedures and anastomoses checked for bleeding

\begin{tabular}{|c|c|c|c|c|c|c|c|}
\hline \multirow[t]{3}{*}{ Replaced aorta } & \multicolumn{3}{|c|}{ No. of subjects } & \multirow[t]{3}{*}{ Anastomotic site } & \multicolumn{3}{|c|}{$\begin{array}{l}\text { No. of anastomo- } \\
\text { ses }\end{array}$} \\
\hline & \multicolumn{2}{|c|}{ Group } & \multirow[t]{2}{*}{ Total } & & \multicolumn{2}{|c|}{ Group } & \multirow[t]{2}{*}{ Total } \\
\hline & $\mathrm{S}$ & $\mathrm{C}$ & & & $\mathrm{S}$ & $\mathrm{C}$ & \\
\hline \multirow[t]{4}{*}{ Ascending aorta } & \multirow[t]{4}{*}{12} & \multirow[t]{4}{*}{5} & \multirow[t]{4}{*}{17} & Proximal & 12 & 5 & 17 \\
\hline & & & & Graft-to-graft & 3 & 1 & 4 \\
\hline & & & & Distal & 11 & 5 & 16 \\
\hline & & & & Subtotal & 26 & 11 & 37 \\
\hline \multirow[t]{5}{*}{ Ascending aorta \& partial aortic arch } & \multirow[t]{5}{*}{4} & \multirow[t]{5}{*}{0} & \multirow[t]{5}{*}{4} & Proximal & 4 & 0 & 4 \\
\hline & & & & Graft-to-graft & 3 & 0 & 3 \\
\hline & & & & BCA & 3 & 0 & 3 \\
\hline & & & & Distal & 3 & 0 & 3 \\
\hline & & & & Subtotal & 13 & 0 & 13 \\
\hline \multirow[t]{8}{*}{ Total aortic arch } & \multirow[t]{8}{*}{26} & \multirow[t]{8}{*}{16} & \multirow[t]{8}{*}{42} & Proximal & 26 & 16 & 42 \\
\hline & & & & Graft-to-graft (proximal) & 0 & 1 & 1 \\
\hline & & & & BCA & 26 & 16 & 42 \\
\hline & & & & LCCA & 25 & 16 & 41 \\
\hline & & & & LSCA & 26 & 15 & 41 \\
\hline & & & & Graft-to-graft (distal) & 16 & 12 & 28 \\
\hline & & & & Distal & 11 & 12 & 23 \\
\hline & & & & Subtotal & 130 & 88 & 218 \\
\hline \multirow[t]{7}{*}{ Total aortic arch \& descending aorta } & \multirow[t]{7}{*}{0} & \multirow[t]{7}{*}{1} & \multirow[t]{7}{*}{1} & Proximal & 0 & 1 & 1 \\
\hline & & & & BCA & 0 & 1 & 1 \\
\hline & & & & LCCA & 0 & 1 & 1 \\
\hline & & & & LSCA & 0 & 1 & 1 \\
\hline & & & & Graft-to-graft & 0 & 1 & 1 \\
\hline & & & & Distal & 0 & 1 & 1 \\
\hline & & & & Subtotal & 0 & 6 & 6 \\
\hline \multirow[t]{5}{*}{ Descending aorta } & \multirow[t]{5}{*}{12} & \multirow[t]{5}{*}{5} & \multirow[t]{5}{*}{17} & Proximal & 10 & 5 & 15 \\
\hline & & & & Graft-to-graft & 1 & 0 & 1 \\
\hline & & & & Distal & 11 & 5 & 16 \\
\hline & & & & Intercostal artery & 5 & $2 *$ & 7 \\
\hline & & & & Subtotal & 27 & 12 & 39 \\
\hline Total & 54 & 27 & 81 & Total & 196 & 117 & 313 \\
\hline
\end{tabular}

$B C A$ brachiocephalic artery, $L C C A$ left common carotid artery, $L S C A$ left subclavian artery

*One of the anastomoses to the intercostal artery had "Graft-to-Graft" anastomosis
Significant differences in secondary endpoints were found in the incidence of an additional hemostatic procedure, which included additional surgical stitch placement or the application of hemostatic agents to the anastomosis. The amount of transfusion, especially the amount of fresh-frozen plasma used during the operation, tended to be smaller in Group S than in Group C, but not to a significant degree (Table 4).

\section{Adverse events}

There were five hospital deaths: three deaths in Group S (hospital mortality rate 5.7\%) and two deaths in Group C (7.4\%). The causes of deaths in Group S were pneumonia, multiple organ failure, and mediastinitis following skin wound contamination. With regard to the patient who died of mediastinitis, CT taken 20 days after total aortic arch showed no sign of infection in the mediastinum. The skin wound infection occurred after 4 weeks of surgery. We thus speculated that the source or origin of infection was the skin, not the anastomosis. 
Table 3 Number of complete hemostasis (no bleeding) according to the type of anastomosis

\begin{tabular}{|c|c|c|c|c|c|}
\hline \multirow[t]{3}{*}{ Anastomotic site } & \multirow[t]{3}{*}{ Replaced aorta } & \multicolumn{3}{|c|}{ No. of anastomoses } & \multirow{3}{*}{$\begin{array}{l}\chi^{2} \text { test } \\
(p \text { value })\end{array}$} \\
\hline & & \multicolumn{2}{|l|}{ Group } & \multirow[t]{2}{*}{ Total } & \\
\hline & & $\mathrm{S}$ & $\mathrm{C}$ & & \\
\hline \multirow[t]{10}{*}{ Aorta-to-graft } & Ascending proximal & 42 & 22 & 64 & \\
\hline & Ascending distal & 11 & 5 & 16 & \\
\hline & Partial arch distal & 3 & 0 & 3 & \\
\hline & Descending distal & 11 & 12 & 23 & \\
\hline & Descending proximal & 10 & 5 & 15 & \\
\hline & Descending distal & 11 & 6 & 17 & \\
\hline & Subtotal & 88 & 50 & 138 & \\
\hline & No bleeding & & & & \\
\hline & Before protamine sulfate & $63(71.6 \%)$ & $16(32.0 \%)$ & - & $<0.001$ \\
\hline & After protamine sulfate & $73(83.0 \%)$ & $27(54.0 \%)$ & - & $<0.001$ \\
\hline \multirow[t]{7}{*}{ Arch vessel } & BCA & 29 & 17 & 46 & \\
\hline & LCAA & 25 & 17 & 42 & \\
\hline & LSCA & 26 & 16 & 42 & \\
\hline & Subtotal & 80 & 50 & 130 & \\
\hline & No bleeding & & & & \\
\hline & Before protamine sulfate & $70(87.5 \%)$ & $24(48.0 \%)$ & - & $<0.001$ \\
\hline & After protamine sulfate & $75(93.8 \%)$ & $34(68.0 \%)$ & - & $<0.001$ \\
\hline \multirow[t]{6}{*}{ Graft-to-graft } & Proximal & 5 & 2 & 7 & \\
\hline & Distal & 18 & 13 & 31 & \\
\hline & Subtotal & 23 & 15 & 38 & 0.004 \\
\hline & No bleeding & & & & \\
\hline & Before protamine sulfate & $17(73.9 \%)$ & $4(26.7 \%)$ & - & \\
\hline & After protamine sulfate & $20(87.0 \%)$ & $8(53.3 \%)$ & - & 0.021 \\
\hline \multirow[t]{4}{*}{ Intercosta 1 artery } & Subtotal $*^{1}$ & 5 & 2 & 7 & \\
\hline & No bleeding & & & & \\
\hline & Before protamine sulfate & $5(100.0 \%)$ & $1(50.0 \%)$ & - & 0.088 \\
\hline & After protamine sulfate & $5(100.0 \%)$ & $2(100.0 \%)$ & - & N/A \\
\hline Total & & 196 & 117 & 313 & \\
\hline \multirow[t]{2}{*}{ No bleeding } & Before protamine sulfate & $155(79.1 \%)$ & $45(38.5 \%)$ & - & $<0.001$ \\
\hline & After protamine sulfate & $173(88.3 \%)$ & $71(60.7 \%)$ & - & $<0.001$ \\
\hline
\end{tabular}

*1, One graft-to-graft anastomosis is included in subtotal number
The causes of the two deaths in Group $\mathrm{C}$ were intraoperative stroke and sepsis following cholangitis.

Among the patients who were discharged, there were no deaths during the 6-month follow-up period. The complications observed during the follow-up period are shown in Table 5. There were no significant differences in the incidence of each complication between the two groups.

\section{Discussion}

In the present study of aortic aneurysm repair using cardiopulmonary bypass, patients whose anastomoses were treated with the sealant showed a significantly higher complete hemostasis rate than the control group patients who received standard surgical care. These results are very encouraging, as thoracic aorta replacement still carries high morbidity and mortality rates despite technological advances [9, 10], with this high risk being largely related to intraoperative bleeding. The nature of the disease, which is often complicated by a frail aortic wall in aortic dissection or inherent coagulation disorders, makes the situation worse [11]. The current sealant exerts its hemostatic property independent of the host coagulation system, as evidenced by the high hemostasis rate evaluated before protamine sulfate administration. Although the current study design allowed for the enrollment of patients who underwent elective repair of true aneurysm without preoperative coagulation disorders, the results highlight the promising features of the sealant when used in corrective surgery for acute aortic dissection 

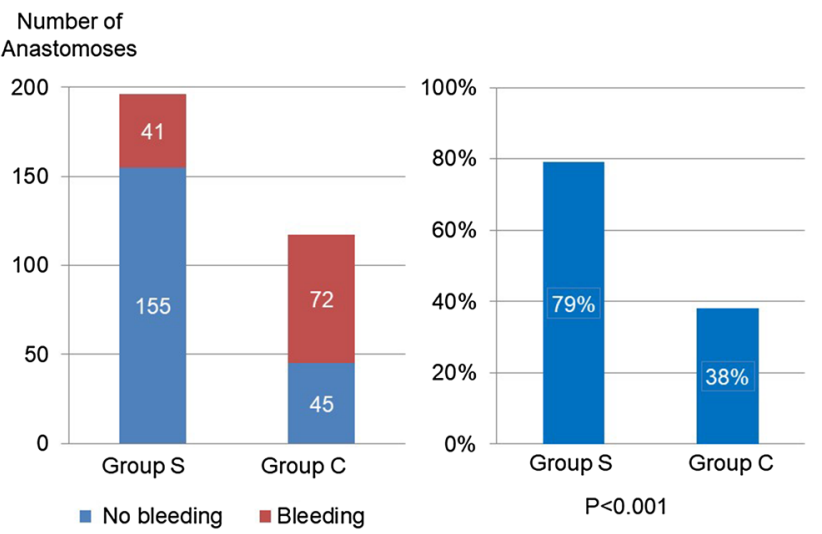

Fig. 4 Hemostatic condition at the anastomoses before protamine sulfate administration. The right bar graph shows the complete hemostasis rates

or impending rupture of an aortic aneurysm, in which the coagulation system is jeopardized.

The sealant discussed in this study, diisocyanate-endcapped prepolymer, has several unique features. Its hydrophilic property allows the sealant to penetrate gaps or needle holes where water molecules exist and start to polymerize by reacting with water. This produces an anchored seal attached to the site of anastomosis, thereby resulting in highly efficient hemostasis, as shown in a previous animal experiment. In that experiment, the sealant completely controlled the bleeding from an end-to-end anastomosis of a porcine carotid artery made with four stitches of simple interrupted sutures [8]. The efficient hemostatic property observed in our animal experiment was confirmed in the current study to be just as effective in the clinical setting of thoracic aorta surgery.

The sealant does not require the mixing of two agents, such as fibrin glue or BioGlue, to kick-start a reaction. Instead, the reaction is initiated by contact with water, similar to cyanoacrylate. However, the cured material after polymerization is quite different between these two agents. For example, cyanoacrylate has no elastomeric properties, whereas the current sealant is elastomeric, allowing the arterial anastomosis to pulsate. In our animal experiment, the inelastic property of cyanoacrylate caused thinning of the arterial wall, whereas the application of the current sealant to the aortic wall did not cause any thinning of the abdominal aorta [8]. It should be noticed that the sealant expands after the completion of curing process. According to the maker's data, it expands $46 \%$ in length and $210 \%$ in volume. Excessive use of the sealant should be avoided because when CT is taken after surgery, substantial layer of the sealant
Table 4 Results of secondary endpoints

\begin{tabular}{llll}
\hline Secondary endpoints & $\begin{array}{l}\text { Group S }\left(N=53^{\mathrm{a}}\right) \\
\text { Mean (S.D.) }\end{array}$ & $\begin{array}{l}\text { Group C }(N=27) \\
\text { Mean (S.D.) }\end{array}$ & $p$ value \\
\hline $\begin{array}{l}\text { Operation time after protamine administra- } \\
\text { tion (min) }\end{array}$ & $137(46)$ & $141(64)$ & 0.815 \\
Blood loss & & & \\
On gauze pads (g) & $749(531)$ & $675(341)$ & 0.453 \\
Collected for auto transfusion (mL) & $220(822)$ & $378(845)$ & 0.423 \\
Chest tube drainage & $473(314)$ & $391(270)$ & 0.252 \\
Transfusion & & & 0.535 \\
Packed red cells (units) & $5.7(4.4)$ & $6.4(5.0)$ & 0.057 \\
Fresh-frozen plasma (units) & $6.0(4.9)$ & $8.4(6.2)$ & 0.407 \\
Platelets & $7.4(7.9)$ & $9.3(10.4)$ & \\
Number of anastomoses & 196 & 117 & $<0.001$ \\
Additional hemostatic procedure & $38(19.4 \%)$ & $65(55.6 \%)$ & 0.008 \\
Additional stitches & $20(10.2 \%)$ & $25(21.4 \%)$ & N.A. \\
Reapplication of the sealant & $1(0.5 \%)$ & N.A. & $<0.001$ \\
Use of other hemostatic agents & $26(13.3 \%)$ & $58(49.6 \%)$ & $<0.001$ \\
Fibrin sealant (L) & $20(10.2 \%)$ & $56(47.9 \%)$ & $<0.001$ \\
Fibrin sealant (S) & $10(5.1 \%)$ & $36(30.8 \%)$ & $<0.001$ \\
Thrombin & $0(0.0 \%)$ & $9(7.7 \%)$ & $<0.001$ \\
Oxycellulose & $1(0.5 \%)$ & $3(2.6 \%)$ & 0.118 \\
Wrapping & $1(0.5 \%)$ & & \\
\hline
\end{tabular}

${ }^{a}$ One patient was excluded from the endpoint analysis because of bleeding from the injured pulmonary artery. Thus, the number evaluated is 53 instead of 54 . The bleeding was considered to be unrelated to the bleeding from the anastomosis where the sealant had been applied

${ }^{b}$ Fibrin sealant (L): liquid type fibrin sealant, fibrin sealant (S): sheet type fibrin sealant 
Table 5 Adverse events

\begin{tabular}{lcll}
\hline Items & Group S $\left(N=53^{\mathrm{a}}\right)$ & $\begin{array}{l}\text { Group C }(N=27) \\
N(\%)\end{array}$ & $p$ value \\
\hline Deaths & $N(\%)$ & $2(7.4)$ & 1.000 \\
Pleural effusion & $3(5.7)$ & $6(22.2)$ & 0.308 \\
Pericardial effusion & $19(35.8)$ & $1(3.7)$ & 0.260 \\
Paraparesis & $8(15.1)$ & $0(0)$ & 1.000 \\
Stroke & $1(1.9)$ & $3(11.1)$ & 0.683 \\
Atrial fibrillation & $4(7.5)$ & $4(14.8)$ & 0.726 \\
Bleeding requiring resternotomy & $6(11.3)$ & $0(0)$ & 1.000 \\
Mediastinitis & $1(1.9)$ & $1(3.7)$ & 1.000 \\
Pneumonia & $3(5.7)$ & $1(3.7)$ & 0.658 \\
Respiratory failure requiring tracheostomy & $4(7.5)$ & $0(0)$ & 1.000 \\
Renal failure requiring dialysis & $1(1.9)$ & $0(0)$ & 0.547 \\
\hline
\end{tabular}

${ }^{\text {a }}$ Please refer to the explanation in Table 4 for the reason the number is 53 instead of 54

mimics free air around the anastomosis, which makes it difficult to diagnose infection.

The current results are very favorable compared to those of previous reports regarding hemostatic agents. Cosselli et al. reported a series of patients whose anastomoses were treated with a protein-based tissue adhesive [1]. The hemostasis rate in their study was $81 \%$ in a mix of patients who underwent cardiac, aortic, and peripheral vascular procedures. In their series, nearly half of the patients did not require cardiopulmonary bypass, whereas in the current series, cardiopulmonary bypass was used in all patents and the surgical procedure was limited to aortic aneurysm repair, one of the most invasive operations in the field of cardiovascular surgery. Glickman et al. performed a randomized controlled trial showing equivalent sealing success with a polymeric sealant and a gelfoam/thrombin hemostatic agent [4]. The patients underwent either infrainguinal revascularization or the start of dialysis. In their series, heparin was used in more than $90 \%$ of cases and approximately $50 \%$ of the patients had intraoperative heparin reversal with protamine, but none was on cardiopulmonary bypass. An encouraging point of our study is that a hemostatic effect of the sealant was observed immediately after coming off of cardiopulmonary bypass, when patients were still fully heparinized. This result indicates that the sealant exerts its effect independent of the blood coagulation capacity, implying that it will be effective even in tough situations, such as in patients with acute aortic dissection, impending aortic aneurysm rupture, or severe perioperative coagulopathy.

Although the difference in the amount of bleeding did not reach statistical significance, had a larger number of patient been included, the results might have been different, as the $p$ value was relatively small, especially for fresh-frozen plasma ( $p=0.057$ ). Post-marketing surveillance with 538 patients showed that the hemostatic function of the sealant was highly effective in $90.1 \%$ of the cases (data submitted to PMDA). Although the surveillance is not a randomized trial, we are highly convinced that the sealant is effective in controlling the bleeding clinically.

Assumptions concerning the issue of patient number should be made carefully, as while the difference did not reach statistical significance, the incidence of pleural effusion and pericardial effusion tended to be higher in Group S than in Group C. Currently, post-marketing surveillance has been completed under the guidance of the PMDA. The surveillance enrolled more than 500 patients and 1-year followup has been completed. The incidence of pleural effusion in the surveillance was $15.1 \%$ (87/576), which was not markedly different from the incidence of pleural effusion in the control group of this study (22.2\%). Similarly, the incidence of pericardial effusion in post-marketing surveillance was $4.3 \%$ (25/576), which was not significantly different from the incidence in Group C (3.7\%). Based on these data, we assume that pleural and pericardial effusions are not adverse effects specifically related to the sealant. But because of its non-absorbable nature, continuing attention should be payed as same as the other devices or prosthesis designed to remain in the human body.

Several limitations associated with the sealant should be noted. The sealant cannot be pressed with gauze pads or directly touched with gloved fingers, as the sealant strongly adheres to such materials, so if you try to remove the gauze or gloves, it will remove the adventitia attached to the pad. It is therefore recommended that the sealant be pressed over a silicon strip (which does not adhere to the sealant) that can then be removed after the sealant has completely cured, which requires no longer than $3 \mathrm{~min}$. In addition, the study was limited by its open label, non-blinded protocol. Another limitation of note is that the primary endpoints were judged by the inspection by surgeons, whose opinion may have been biased by the open-label nature of the study. However, given the high significant difference in the hemostatic rate between 
the groups, we consider the results to be reliable despite the fact that the evaluation relied on surgeons' inspection.

Usage of the sealant with or without Teflon felt reinforcement should be noted. Applying the sealant over Teflon felt caused no problem. Indeed, Teflon and the polymerized sealant have a high affinity, which may enhance the sealing property. However, the usage of Teflon felt is not a prerequisite. Because "graft-graft" anastomosis, which does not require Teflon felt, as depicted in Table 2 was equally wellmanaged by directly applying the sealant to the anastomosis. The hemostasis rate in "graft-graft" anastomosis was similarly high $(73.9 \%, 17 / 23)$.

\section{Conclusion}

The elastomeric sealant was highly effective and safe when used in thoracic aorta surgery. Further study is warranted to test its efficacy in sicker patients such as with acute aortic dissection or impending rupture of the thoracic aorta.

\section{Compliance with ethical standards}

Conflict of interest The work was supported by Sanyo Chemical Industries, Ltd., as a clinical trial. One of the authors (S.M.) serves as a consultant to Sanyo Chemical Industries, Ltd. The rest of the authors have no conflict of interest. All authors have full control of all primary data and that they agree to allow the journal to review the data if requested.

Open Access This article is distributed under the terms of the Creative Commons Attribution 4.0 International License (http://creativeco mmons.org/licenses/by/4.0/), which permits unrestricted use, distribution, and reproduction in any medium, provided you give appropriate credit to the original author(s) and the source, provide a link to the Creative Commons license, and indicate if changes were made.

\section{References}

1. Coselli JS, Bavaria JE, Fehrenbacher J, Stowe CL, Macheers SK, Gundry SR. Prospective randomized study of a protein-based tissue adhesive used as a hemostatic and structural adjunct in cardiac and vascular anastomotic repair procedures. J Am Coll Surg. 2003;197:243-52.

2. Lumsden AB, Heyman ER. Prospective randomized study evaluating an absorbable cyanoacrylate for use in vascular reconstructions. J Vasc Surg. 2006;44:1002-9.

3. Rousou J, Levitsky S, Gonzalez-Lavin L, Cosgrove D, Magilligan $\mathrm{D}$, Weldon $\mathrm{C}$, et al. Randomized clinical trial of fibrin sealant in patients undergoing resternotomy or reoperation after cardiac operations. A multicenter study. J Thorac Cardiovasc Surg. 1989;97:194-203.

4. Glickman M, Gheissari A, Money S, Martin J, Ballard JL. A polymeric sealant inhibits anastomotic suture hole bleeding more rapidly than gelfoam/thrombin. Arch Surg. 2002;137:326-31.

5. Matsuda T, Itoh T, Yamaguchi T, Iwata H, Hayashi K, Uemura S, et al. A novel elastomeric surgical adhesive: design, properties, and in vivo performances. ASAIO Trans. 1986;32:151-6.

6. Matsuda T, Nakajima N, Itoh T, Takakura T. Development of a compliant surgical adhesive derived from novel fluorinated hexamethylene diisocyanate. ASAIO Trans. 1989;35:381-3.

7. Eto M, Morita S, Sugiura M, Yoshimura T, Tominaga R, Matsuda T. Elastomeric surgical sealant for hemostasis of cardiovascular anastomosis under full heparinization. Eur J Cardiothorac Surg. 2007;32:730-4.

8. Oda S, Morita S, Tanoue Y, Eto M, Matsuda T, Tominaga R. Experimental use of an elastomeric surgical sealant for arterial hemostasis and its long-term tissue response. Interact Cardiovasc Thorac Surg. 2010;10:258-61.

9. Motomura N, Miyata H, Tsukihara H, Takamoto S. Risk model of thoracic aortic surgery in 4707 cases from a nationwide singlerace population through a web-based data entry system: the first report of 30-day and 30-day operative outcome risk models for thoracic aortic surgery. Circulation. 2008;118(14 Suppl):S153-9.

10. Masuda M, Kuwano H, Okumura M, Arai H, Endo S, Doki Y, et al. Thoracic and cardiovascular surgery in Japan during 2013: annual report by the Japanese association for thoracic surgery. Gen Thorac Cardiovasc Surg. 2013;63:670-701.

11. Paparella D, Rotunno C, Guida P, Malvindi PG, Scrascia G, De Palo M, et al. Hemostasis alterations in patients with acute aortic dissection. Ann Thorac Surg. 2011;91:1364-9.

Publisher's Note Springer Nature remains neutral with regard to jurisdictional claims in published maps and institutional affiliations. 